Segunda Parte Direito Privado e Processual 


\section{Reflexões Sobre a ResoluÇÃo do Contrato na Nova Teoria Contratual ${ }^{1}$}

\section{Clarissa Costa de Lima}

Sumário. Introdução. I) Perfil do Direito à Resolução por Inadimplemento. A) Conceito e Enquadramento Legal, B) Pressupostos da Resolução; b.1) contrato bilateral; b.2) inadimplemento absoluto: incumprimento definitivo da obrigação; b.3) não-inadimplência do credor. II) Controle Judicial da Resolução por Inadimplemento. A) Intepretação do Instituto à Luz da Boa-Fé Objetiva: Instrumento de Inclusão Social. B) Valorização da Catividade nos Contratos de Consumo e Obrigação de Renegociat. Considerações Fìnais. Referência Bibliográficas.

\section{INTRODUÇÃO}

O inadimplemento pode levar à extinção prematura do vínculo contratual através de sua resolução. Segundo Agostinho Alvim, a resolução é a parte patológica do direito obrigacional e em nenhum outro campo o juiz encontra melhor oportunidade de executar o poder discricionário que a lei lhe concede.

Tomando-se como ponto de partida essas preciosas considerações, a exposição será desenvolvido em duas partes. Na primeira, mais teórica, pretendemos traçar um panorama geral da resolução do contrato por inadimplemento, conceituando o instituto, estabelecendo seus pressupostos e seu âmbito de aplicação no Direito das Obrigações. Nesta etapa merecerá especial atenção a questão da mora que é de grande importância prática e cuja caracterização tem sido muito debatida na doutrina e nos Tribunais.

1 O presente trabalho foi apresentado na disciplina "Teotia Contratual" da pós graduação em Direito da UFRGS, ministrada pelo Dr. Ruy Rosado de Aguiar Júnior e Dra. Cláudia Lima Marques no $2^{\circ}$ semestre de 2004.

2 Juíza de Direito Estadual, mestranda em Direito na Universidade Federal do Rio Grande do Sul. 
A segunda parte do trabalho será dedicada à a tividade desenvolvida pelo juiz quando se utilizar do remédio excepcional da resolução contratual. Procuraremos demonstrar a necessidade de compatibilização do instituto com o princípio da boa-fé objetiva para que seja mantido o justo equilíbrio entre as partes contratantes. Nesta altura traremos à baila interessantes julgados pesquisados no intuito de verificar como a resolução estaria sendo aplicada pelo Tribunal de Justiça Gaúcho.

Por fim, merece destaque a análise da resolução tendo-se como cenátio os contratos de consumo de longa duração, suscetiveis às vicissitudes do tempo, nos quais a boa-fé assume potencialidade máxima através da criação dos deveres de cooperação e renegociação do contrato com o fim de reestabelecer o equilibrio entre as partes, de forma a evitar o superendividamento com a ruina do contrarante mais fraco.

\section{PERFIL DO DIREITO À RESOLUÇÃO POR INADIMPLEMENTO}

\section{A. Conceito e Enquadramento Legal}

A resolução é o modo de extinção da relação obrigacional estabelecida em contrato bilateral, com a retirada de sua eficácia pelo exercício do direito formativo-extintivo, do qual é titular o credor não-adimplente, fundado no incumprimento definitivo do devedor e imputável a este.

O Código Civil de 1916 tratava da resolução, enganosamente denominada da rescisão no parágrafo único do art. 1.092, juntamente com as exceções "non adimpleti contractus" e "non rite adimpleti contractus" que eram tratadas no caput do mesmo dispositivo. Confira-se:

Nos contratos bilaterais, nenhum dos contratantes, antes de cumprida a sua obrigação, pode exigir o implemento da do outro.

Se depois de concluido o contrato sobrevier a uma das partes contratantes diminuição em seu patrimônio, capaz de comprometer ou tornar duvidosa a prestação pela qual se obrigou, pode a parte, a quem incumbe fazer prestação em primeiro lugar, recusar-se a esta, até que a outra satisfaça a que the compete ou dê garantia bastante de satisfazê-la.

O Novo Código Civil de 2.002 adotou melhor técnica legislativa, localizando o instituto no capítulo dedicado à Extinção do Contrato e regulando-o na seção " $\mathrm{Da}$ Cláusula Resolutiva", separada das exceçōes supracitadas que foram contempladas em seção autônoma: "Da Exceção do Contrato Não Cumprido". Assim dispõe o art. 475: 
A parte lesada pelo inadimplemento pode pedir a resolução do contrato, se não prefent exigir-lhe o cumprimento, cabendo, em qualquer dos casos, indenização por perdas e danos.

O novo dispositivo legal, segundo Araken de Assis, se assemelha ao parágrafo único do art. 1092 porque manteve o caráter facultativo do remédio, além de invocar o inadimplemento regulando seus efeitos. $\mathrm{E}$ diverge do modelo anterior em pontos expressivos: a localização da regra deixa claro que há dissolução do contrato, não se inferindo, por idêntico motivo, que a resolução se aplique, exclusivamente, ao contrato bilateral, além disso empregou a palavra correta "resolução" ao invés de "tescisão".

Da definição supra de autoria do Ministro Ruy Rosado de Aguiar Júnior se extraem os pressupostos para a resolução dos contratos que a seguir serão analisados.

\section{B. Pressupostos da resolução}

\section{Contrato Bilateral}

O Código Civil de 1916 tratava da resolução no capítulo dos contratos bilaterais (capítulo II, Título, IV, "Dos Contratos"). O Código Civil de 2.002 cuida da resolução no capitulo da extinção dos contratos, sem referir sobre o contrato ser ou não bilateral. Apesar desta alteração legislativa, à falta de regra em sentido contrário, pode-se concluir que continua vigorante o princípio de que a resolução é o modo de extinção de contratos bilaterais.explícito apenas da exceção do contrato não cumprido (art. 476). ${ }^{4}$

Latenz define o contrato bilateral como sendo aquele em que ambas as partes contraem obrigações e ao menos alguns dos seus deveres recíprocos de prestação estão vinculados entre si, de modo que a prestação de uma representa, de acordo com a vontade de ambas as partes, a contraprestação, a compensação pela outra.

Essa interdependência ou correspectividade deve estar presente na celebração do contrato(sinalagma genético) e também durante sua execução (sinalgama funcional), uma vez que o fundamento da extinção da relação obrigacional pela via resolutiva reside na exigência de ser mantido o justo equilibrio entre as partes contratantes.

Araken de Assis diverge em certa medida ao sustentar que a aplicação do instituto não equivale à do contrato bilateral, e sim, à da reciprocidade prestacional, chegando a afirmar que :

3 Veremos mais adiante que o Ministro Ruy Rosado de Aguiar Júnior sustenta, ao revés, que o instituto da resolução permanece ligado aos contratos bilaterais. In "A lixtinção dos Contratos por incumprimento do devedor". Rio de Janeiro: Aide Editora, 2003, p.83

4 A conclusão é do Ministro Ruy Rosado de Aguiar Júnior na obra já citada 
Se, de um lado, a presença de uma bilateralidade principalitercontrato bilateral- não enseja a resolução, caso a prestação debitória descumprida não lhe corresponda ou não esteja em posição de reciprocidade, de outro nada obsta quie os parceiros, aluto-regrando o conteúdo do contrato, convenham em estipular essa reciprocidade, ou, convencionalmente, acordem que o descumprimento da prestação sem reciprocidade implique, contudo,a resolução. ${ }^{5}$

\section{Inadimplemento Absoluto: Incumprimento Definitivo da Obrigação}

Clóvis do Couto e Silva ${ }^{6}$ examina a telação obrigacional como algo que se encadeia e se desdobra em direção ao adimplemento, à satisfação dos interesses do credor. $\mathrm{O}$ adimplemento, pois, é a regra, "atrai e polariza a obrigação".

Agostinho Alvim chega a arrolar vários motivos que levam o contratante a cumprir o que prometeu desde a simples ética até o temor da reprovação pública. ${ }^{7}$ O inadimplemento, contudo, pode levar à extinção prematura do vínculo contratual através da resolução.

Aqui se faz necessário mencionar as duas espécies de inadimplemento: inadimplemento absoluto e inadimplemento-mora tradicionalmente nomeado de inadimplemento relativo. O estudo e a distinção de ambas as espécies é de extrema relevância especialmente quanto aos seus efeitos já que somente a primeira autoriza a resolução do contrato, mediante opção do credor. A simples mora não autoriza a resolução do contrato até porque a própria lei somente permite ao credor enjeitar a prestação ofertada após o vencimento, se esta se mostrar inútil (art.395\$ único do Código Civil).

Grande parte da doutrina defende que o conceito jurídico de mora no direito brasileiro tesulta da conjugação dos arts. 394 e 396 do Código Civil, os quais transcrevo para melhor análise:

Art. 394. Considera-se em mora o devedor que não efetuar o pagamento e o credor que não quiser recebê-lo no tempo, lugar e forma que a lei ou a convenção estabelecer.

Art. 396. Não havendo fato ou omissão imputável ao devedor, não incorre este em mora.

5 ASSIS, Araken de. Resoluçäo do contrato por inadimplenento. São Paulo: Revista dos Tribunais, 2004, p. 27.

- SILVA, Clóvis do Couto e. A obrigação como processo. São Paulo: Bushstasky, 1976, p. 5

7 ALVIM, Agostinho. Da inexccução das obrigações e suas consequiências. 4. ed. São Paulo: Saraiva, 1972 
No ptimeiro dispositivo legal encontramos os elementos objetivos da mora e no segundo o elemento subjetivo, qual seja, a culpa. Agostinho Alvim, na melhor obra que trata da matéria, sustenta que a culpa é um elemento indispensável para a caracterização da mora. Tanto que a mora deixaria de existir por falta do elemento subjetivo. ${ }^{8}$

Modernamente a matéria continua despertando interesse e suscitando controvérsias. Judith Martins-Costa ensina que a noção de mora do art. 394 do C.C é ampla e flexivel, abarcando todos os casos de descumprimento da obrigação principal, de deveres secundários, laterais, anexos ou instrumentais, correspondendo ao "modo de ser" integral da prestação. Também pode ser inadimplido o dever de lealdade ou dever de informação, instrumentalmente necessário ao cumprimento da prestação devida (deveres de proteção).

No que tange porém ao aspecto subjetivo, a mesma autora defende que a culpa não é elemento imprescindivel para a caracterização da mora, constituindo um importante critério que informa o nexo de imputação de responsabilidade entre o fato do não-cumprimento imputável e a sua conseqüência, qual seja, a responsabilidade. Quanto ao conceito de culpa ainda refere que:

Hoje, diversamente, o problema central é a superação deste conceito rigoroso, evidentemente inadaptado às necessidades do comércio jurídico e incompatível com a cláusula geral da boa-fé. Para tanto, exigi-se que o limite da responsabilidade do devedor seja avaliado relativamente ao inteiro conteúdo da relação obrigacional e, assim sendo, em estreita conexão com o regulamento negocial em causa e os interesses econômicos que the estão subjacentes.

Este já era o entendimento de Pontes de Miranda que defende a possibilidade de haver mora sem culpa, referindo inclusive que os assuntos deveriam ser tratados separadamente, Em sua opinião, o art. 963 do Código Civil de 1916, a que no Código Civil de 2002 corresponde ao art. 396, foi redigido para que o direito brasileiro tomasse posição: ou a) exigir o elemento da culpa, ou b) não o exigir. Adotou-se a segunda atitude, que é a do princípio da imputabilidade ou da causação (Veranlassungsprinzip), em vez do princípio da culpa (Verschuldensprinzip). ${ }^{\text {t" }}$

B Na página 19 encontratros o exemplo do devedor que não sabe onde deve pagar por haver o credor se reservado o direito de fazer essa indicação posteriormente, enquanto este último permanece inativo, năo há moxa, ainda que o dia do vencimento tenha chegado. (ALVIM, Da inexecuçăo..., p. 19.)

"MARTINS-COST'A, Judith. Comentários ao novo código civil. Rio de Janeiro: Forense, 2003, v. 5, t. 2, p. 225.

11 MIRANDA, Francisco Cavalcanti Pontes de. Tratado de direito privado. Rio de Jageiro: Bookseller, 2003 , v. 23 , p. 156 
Conquanto o tema suscite divergências também nos tribunais, se verifica major inclinação da jurisprudência pela doutrina de Agostinho Alvim, a qual sustenta que a mora não se caracteriza pela simples imputação, sendo a culpa elemento essencial de seu conceito.

Calba aqui a decisão do Superior Tribunal de Justiça, em acórdão da lavra do Ministro Ruy Rosado de Aguiar, proferido no recurso especial n ${ }^{\circ} 82560-S P$, de onde se lê:

Sabe-se que a mora, no nosso sistema exige o elemento subjetivo, pois só existe mota culposa (art. 963 do CC). Já ensinava Orosimbo Nonato, na sua linguagem enxuta: "como quer que seja, em nosso Direito, e em face dos textos legais citados, o tema não comporta dúvidas ou entredúvidas. Exato desconter o artigo 955 do Código Civil alusão à culpa: considera-se em mora o devedor que não paga ou o credor que não recebe, no tempo, lugar e forma convencionados. Mas o art. 963, complementar do 955, dispõe às expressas: Não havendo fato ou omissão imputável ao devedor, não incorre este em mora [...] Ampla e constante, iterada e reiterada tem sido na jutisprudência dos tribunais a aplicação do art. 963 suso transerito."

Já o inadimplemento absoluto se caracteriza quando a obrigação não foi cumprida, nem poderá sê-lo. O critério específico da distinção entre os inadimplemento absoluto e relativo reside na possibilidade, ou não, de o credor receber a prestação. Tanto é assim que o parágrafo único do art. 395 do C.C reza que "Se a prestação, devido à mora, se totnar inútil ao credor, este poderá enjeitá-la, e exigir a sarisfação das perdas e danos."

A inutilidade que a lei cogita em matéria de mora não é a da inutilidade objetiva da prestação, inutilidade para qualquer pessoa que se confunde com operecimento do objeto, mas a inutilidade para o credor, entrando aí um subjetivismo que deverá ser apreciado caso a caso pelo juiz. ${ }^{12}$

Alguns exemplos são, por si só, esclarecedores: (a) Pedto se obrigou a entregar a Mário um automóvel que, entretanto, pereceu em razão do mau uso; (b) Artur se comprometeu a fazer mágicas na festa de aniversátio do filho de Paulo e não compareceu a ela; (c) Fernando, obrigado pelo saldo do preço do automóvel, caiu em insolvência. ${ }^{13}$

11 Curso de Obrigaçòes, $2^{a}$ parte, V. Y/300; no mesmo sentido OPTIZ, Oswaldo. Mora no negócio jurídico. São Paulo: Saraiva, 1984 p.12 e MONTERRO, Washington de Barros. Curso de Direito Civil

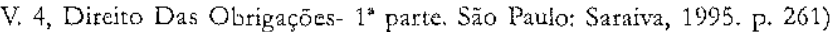

12 Conceito de ALVIM, $D_{a}$ inexecução..., p. 54

13 ASSiS, Resolução do contrato..., P. 102. 
Algumas vezes a mora pode vir a se constituir em incumprimento definitivo ou inadimplemento absoluto, autorizando a resolução, quando a ele se agregar a perda de interesse do credor. Exemplo interessante é o da contratação de transporte de um valioso cavalo de São Paulo a Porto Alegre para a cotrida do "Grande Prêmio". O animal é entregue no local convencionado, na data e local estipulados no contrato; todavia, o caminhão onde transportado não tinha cobertura, e o cavalo não fora alimentado. Chega no local convencionado, às vésperas do Grande Prèmio, totalmente exaurido, maltratado pelas adversas condiçôes climáticas que sofrera no percurso, sem condições de participar da competição. Aqui, a prestação, considerada como un complexo de direitos e deveres, explícitos ou implícitos, não foi corretamente adimplida, embora tenha sido cumprida a obrigação principal de entrega no local e data convencionados. ${ }^{14}$

A gravidade do descumprimento, a frustração ou a insatisfação do credor deverão ser cautelosamente avaliados pelo juiz, auxiliando-se especialmente do princípio da boa-fé objetiva, porquanto a lei é omissa neste aspecto, nada referindo sobre o incumprimento de escassa importância como o código italiano ${ }^{15}$ ou sobre o incumprimento das obrigações acessórias e deveres de conduta.

\section{Não- Inadimplência do Credor}

O credor em mora não pode resolver o contrato, pois a resolução existe para proteger a parte não-inadimplente da violação provocada pela outra. Só ao lesado cabe ação, segundo o disposto no art. 475 do C.C. ${ }^{16}$

De acordo com a definição do Ministro Ruy Rosado, não estar en mora significa não ter concortido para a falta definitiva ou temporária da prestação que the é devida e cujo incumprimento é o fundamento da sua ação. Assim, tem o credor o dever secundátio de colaborar para a plena realização do contrato. Descumprindo-o, com ou sem culpa, impossibilitando a prestação ou recusando a oferta, incorre o credor em mora, o que afasta a do devedor e deixa sem fundamento o seu pedido de resolução.

É de se destacar que nenhuma referência faz a lei com relação à culpa como pressuposto da mora do credor e que as divergências de interpretação que surgem da leitura do art. 396 do Código Civil dizem respeito exclusivamente à mora do devedor. ${ }^{17}$

${ }^{14}$ MARTINS-COSTA, Comentários ao novo..., v, 5, t. 2, p. 227.

is Art. 1.455: Importanza dell'inadempimento.-1l contratto non si puó risolvere se l'inadempimento di una delle parti ha scarsa importanza, avuto riguardo allinteresse dell'altra.

16 A parte lesada pelo inadimplemento pode pedir a resolução do contrato.

77 Leia mais sobre os diversos sistemas existentes em direito comparado acerca da culpa como elementar da mora do ctedor na obta de ALVIM, Da inexecução..., p. 23. 
Ao tratar do dever de cooperação do credor para o adimplemento, a professora Cláudia Lima Marques refere que ${ }^{18}$ :

Este dever de cooperar deve também ser cumprido de forma ativa pelo fornecedor (Mitwirlsungspflichten); assim, se o fornecedor está obrigado a cumprit com suas obrigaçoes (por exemplo: reembolsar ou fornecer determinados exames e consultas médicas, entregar determinado bem, executar determinado serviço) não deve dificultar o acesso do consumidor aos seus direitos ou inviabilizar que a prestação seja devida (conhecida, tradicionalmente, como exceptio doli). Deve o fornecedor, igualmente, abster-se de usar ou impor expedientes desnecessátios ou maliciosos, como exigir uma grande série de autorizações, documentos, solicitações só retiráveis em determinados locais, em determinada hora e por decisão arbitrária do próprio fornecedor, exigir comunicações imediatas ou em curto espaço de tempo em matérias que envolvem a integridade física, psíquica da pessoa e seus familiares, e ainda mais, exigindo esta atuação contratual sob pena de perda dos direitos contratuais.

Econclui:

Essas dificuldades excessivas impedem o cumprimento da prestação principal e significam o descumprimento das obrigações acessórias oriundas do contrato e do dever de conduta segundo a boa-fé: descumprir o dever de cooperação, de lealdade, significa inadimplir, mesmo que parcialmente.

A situação é muito bem ilustrada na Apelação Cível 70.005.116.298, Décima Quarta Câmara Cível do TJ/RS, de 27/03/2003 do TJ/RS na qual julgou-se improcedente ação de busca e apreensão fiduciária sob o fundamenro de que nos negócios jurídicos de consumo, a existência de cláusulas viciadas por quebra do princípio da boa-fé objetiva, abuso de poder econômico, excesso de onerosidade e/ou enganosidade, em favor do credor, caracterizam a mora accipiendi. ${ }^{\text {is }}$

Concluindo, o incumprimento do credor pode ser de qualquer espécie: incumprimento definitivo, mora ou cumprimento imperfeito, em todas as suas modalidades, independente da existência de culpa, cuja gravidade terá que ser, igualmente, avaliada pelo juiz à luz da boa fé objetiva.

${ }^{18}$ Contratos no Código de Defesa do Consumidor. São Paulo: RT,2002, p.197

"Confira-se o voto do Rel. Des. Aymoté Roq̣ue Pottes de Mello 


\section{CONTROLE JUDICIAL DA RESOLUÇÃO POR INADIMPLEMENTO}

\section{A. Interpretação do instituto à luz da boa - fé objetiva: instrumento de inclusão social}

A história da importância do princípio da boa fé, nos ensina Clóvis do Couto e Silva, relaciona-se com a da autonomia da vontade. Pode-se mencionar que no século XIX o principio da autonomia foi o thais importante, co conceito de pacta sunt servanda, o seu corolário necessário. A essa amplitude de aplicação correspondeu una profunda testrição no principio da boa fé, resultante do predomínio absoluto do voluntarismo jurídico. ${ }^{20}$

A prevalência da vontade, entretanto, não atende mais às situações da vida moderna, impondo-se uma concepção mais objetiva da relação obrigacional. Quer dizer, a relação obrigacional não pode mais ser medida somente com base na vontade, mas deve considerar os fatos ou as circunstâncias referentes ao contrato, permitindo-se construir objetivamente o regramento do negocio juridico, com a admissão de um dinamismo que escapa, por vezes, até mesmo ao controle das partes.

Neste passo, a professora Claudia Lima Marques ${ }^{21}$ destaca a nova concepção do contrato e uma concepção social deste instrumento jurídico, para a qual não só o momento da manifestação da vontade (consenso) importa, mas onde também e principaimentc os efeitos do contrato na sociedade serão levados em conta e onde a condição social e econômica das pessoas nele envolvidas ganha em importância. À procura do equilíbtio contratual, na sociedade de consumo moderna, o direito destacará o papel da lei como linitadora e como verdadeira legitimadora da autonomia da vontade. A lei passará a proteger determinados interesses sociais, valorizando a confiança depositada no vínculo, as expectativas e a boa fé das parres contratantes.

Daí que, embora o novo dispositivo legal sobre o instituto da resolução não revele uma redação inovadora, sua aplicação ou sua leitura deverá ser feita de acordo com essa nova concepção de contrato no Estado Social em que a vontade perde a condição de elemento nuclear, surgindo em seu lugar elemenro estranho às partes, mas básico para a sociedade como um todo: o interesse social.

Esse intervencionismo cada vez maior do Estado nas relaçōes contratuais, no intuito de relativizar o antigo dogma da autonomia da vontade, encontra fértil aplicação nas relações de consumo em razão da desigualdade sócio- econômica dos contratantes, evitando que a resolução fique ao arbítrio do fornecedor, mas pode ser necessário ou recomendável mesmo nas relaçooes entre civis ou empresários dependendo dos reflexos daquele contrato na economia social.

20 FRADERA, Vera Maria Jacob de (Org). O direito privado brasileiro na visăo de Clóvis do Couto e Silva. Porto Alegre: Livraria do Advogado, 1997, p. 34.

21 Obra já citada, p. 175. 
Nesse último caso, poderá o juiz, por exemplo, deixar de extinguir um contrato pela via resolutiva, ainda que presente cláusula expressa se verificar que a manutenção do contrato é necessária para não abalar atividade de significativa importância e que seu cumprimento não demanda esforço injustificado ou excessivo a nenhuma das partes .

Afinal, ao apreciat as demandas resolutórias, o juiz deve estar atento para a função econômica do contrato, inserida no processo de produção e distribuição de bens e serviços e os reflexos que dela advirão. Há sempre uma perda ào se desfazer o que já estava contratado e incluído em programa de trabalho e criação de riquezas, pois da extinção dos negócios defluirão dạnos que alguém softerả, a serem repassados por indenização, sabendo-se que na ponta final está o consumidor. ${ }^{22} \mathrm{~A}$ esta altura, havendo litígio entre os contratantes, as cláusulas resolutivas devem ser avaliadas e analisadas pelo juiz que terá ampla possibilidade de verificação dos requisitos próprios para a resolução.

Neste contexto, com grande censura intervencionista do Estado quanto ao conteúdo do contrato, surge a boa-fé como norma que não admite condutas que contrariem o mandamento de agir com lealdade e correção, pois só assim sua função social será atingida.

A boa-fé objetiva foi recepcionada pelo novo Código Civil em três dispositivos. ${ }^{2.323}$ Art. 422. Os contratantes são obrigados a guardar, assim na conclusão do contrato, como em sua execução os princípios de probidade e boa-fé.

Art. 113. Os negócios devem ser interpretados conforme a boa-fé e os usos do lugar de sua celebração.

No Código de Defesa do Consumidor, boa-fé é referida como princípio a seguir para a harmonização dos interesses dos participantes da relação de consumo e como critério para a definição da abusividade das cláusulas ${ }^{24}$ :

${ }^{22}$ As reflexões sobre a funçäo econômica do contrato săo do Ministro Ruy Rosado de Aguiar Júnior na obra já citada, p.235. Art. 187. Também comete ato ilícito o titular de um direito que, ao exercêtlo, excede manifestamente os limites impostos pelo seu fim econômico e social, pela boa-fé ou pelos bons costumes.

${ }^{24}$ Art. 4-A Politica Nacional de Relações de Consumo tern por objetivo o atendimento das necessidades dos consumidores, o respeito a sua dignidade, saúde e segurança, a proteção de seus interesses cconômicos, a melhoria da sua qualidade de vida, bem como a transparência e harmonia das relações de consumo, atendidos os seguintes princípios:

III- harmonização dos interesses dos participantes das relaçōes de consumo e compatibilização da proteçăo do consumidor com a necessidade de desenvolvimento económico e tecrológico, de modo a viabilizar os princípios nos quais se funda a ordem econômica (art. 170 da Constituição Federal), sempre com base na boa-fé e equilbrio nas relaçöes entre consumidores e fornecedores. Art. 51- São nulas de pleno direito, entre outras, as clausulas contratuais relativas ao fornecimento de produtos e serviços que:

IV- estabeleçan obrigaçóes consideradas iníquas, abusivas, que coloquem o consunidor em desvantagem exagerada, ou sejam incompativeis com a boa-fé ou a equíidade. 
Discorrendo sobre a importância e âmbito de aplicação do princípio, Larenz refere que: el principio de la buena fe significa que cada uno debe guardar fidelidad a la palabra dada y no defraudar la confianza o abusar de ella, ya que ésta forma la base indispensable de todas las relaciones humanas; supone el conducirse como cábía esperar. de cuantos com pensamiento honrado intervienen en el tráfico como contratantes o participando en él en virtud de otros vínculos jurídicos. ${ }^{25}$

A boa- fé objetiva na nova teoria contratual assume largo dominio de aplicação, mas três funções - que são normalmente estudadas pela doutrina- apresentam reflexos especiais no instituto da resol ução como adiante teremos oportunidade de analisar. ${ }^{26}$

A primeira é uma função criadora, porque cria novos deveres, anexos aos deveres de prestação contratual derivados da vontade, como os deveres de informar, de cuidado, cooperação. A segunda é uma função interpretadora que permite a visão do vínculo obrigacional como uma totalidade ou um processo formado por uma série de atos tendentes a uma finalidade que é a utilidade econônico-social do contrato. A terceira é uma função limiradora, teduzindo a liberdade de atuação dos parceiros contratuais ao definir algumas condutas e cláusulas como abusivas, seja controlando a transferência dos riscos profissionais e libertando o devedor en face da não-tazoabilidade de outra conduta. ${ }^{27}$

No campo do direito de resolução, a boa-fé como norma de inadmissibilidade de exercício de direitos que a contrariem foi bem apreendida, tanto que vem sendo expressac largamente aplicada pelo Tribunal de Justiça/RS nos casos de adimplemento substancial do contrato. Por esta teoria, veda-se a resolução do contrato quando o incumprimento é insignificante em relação ao contrato total como se pode verificar através das seguintes ementas colacionadas a título exemplificativo:

PROMESSA DE COMPRA E VEÑDA. RESOLUÇÃODE CONTRATO. Conforme a jurisprudência desta Corte,

${ }^{25}$ LARENZ, Karl. Derecho de obligaciones. Madrid: Revista de Derecho privado, 1985, w. 1, p. 142.

${ }^{26}$ Sobte o assunto, conferir excelente explicação de MARQULS, Contratos...

27 Judith Martins-Costa observa que durante muito tempo, a doutrina da inadmissibilidade do exercício de direitos subjetivos restou limitada às figuras do abuso de dircito e da excepto doli, esta proveniente do direito romano, aquela de construção da jurisprudência francesa. Uma e outra soluçōes, contudo, a pat de diffeultarem a sistematiaçăo dos variados casos de inadmissibilidade do exercício de direitos, estão ainda ancondas uuma perspectiva subjetivista, marcada pela relação entre o dogma da vontade e a construção do direito subjetivo como a sua mais importante projeção. Por isso a tendência, hoje verificável, de sistematizar estes casos através do recurso à boa-fé objetiva, caminho que se insere na tencência que busca especificar os casos de aplicação da boa-fé objeciva, tornando o princípio menos fuido e de acentuada caráter técnico.(MARTINS-COSTA, Judith. A boa-fé no direito privado. Säo Paulo: Revista dos Tribunais, 2000, p. 455.) 
havendo pagamento de aproximadamente $50 \%$ do valor do contrato mostra-se acertada a sentença que julgou improcedente a ação em função de adimplemento substancial do contrato, porquanto a autora não demonstra disposição em indenizar as acessões realizadas pela promitente compradora de boa-fé, Apelo desprovido. Unânime. ${ }^{2 B}$

APELAÇÃO CÍVEL. AÇÃO DE BUSCA E APREENSÃO (DL $911 / 69$ ), POSSIBILIDADE DE REVISÃO. INCIDÊNCIA DO CDC.JUROS REMUNERATÓRIOS. PAGAMENTO SUBSTANCIAL DO BEM . RETOMADA DO BEM. PREQUESTIONAMENTO. No contrato de abertura de crédito garantido por alienação fiduciária, é certa a incidência do Código de Defesa do Consumidor, como prevê o seu art. $3 .^{\circ}, \S 2^{\circ}$, assim como do art. 145 do Código Civil/ 1916, que autorizam a sua revisão. Não merecem manutenção os juros remuneratórios pactuados em taxa superior a $12 \%$ ao ano, conforme limitação constante no art. $192, \$ 3^{\circ}$, da CF (vigente à época da contratação), no Decreto $22.626 / 33$, no CDC, e diante de ausência de prova de que o financiador tenha autorização do CMN para praticar taxas superiores. Não se mostra cabivel a retomada do bem pelo credor, diante do adimplemento substancial do contrato pelo devedor, cabendo àquele execurar o eventual saldo remanescente. $\mathrm{Na}$ linha decisória do acórdão, não há falar em negativa de vigência a qualquer dispositivo legal. Apelação provida. ${ }^{20}$

AÇÃO REVISIONAL. ENCARGOS MORATÓRIOS PREVISTOS CONTRATUALMENTE. ABUSIVIDADE INOCORRENTE. ADIMPLEMENTO SUBSTANCIAL DAS PRESTAÇÕES NÃO AUTORIZA A RESOLUÇÃO DO CONTRATO. COBRANÇA DO SALDO DEVIDO. CABÍVEL. DEMANDA RESOLUTÓRIA JULGADA IMPROCEDENTE. Sem razão os apelantes quando se insurgem contra os valores cobrados pela apelada, considerando que em nenhum momento eles demonstraram

2B RYO GRANDE DO SUL. Tribunal de Justiça. Apelação Civel $\mathrm{N}^{*} 70009625930$. Relator: Mário Rocha Lopes Filho. Julgado en; 07 out. 2004.

29 RIO GRANDE DO SUL. Tribunal de Justiça. Apelação Civel N 70000682724 . Relator: Lúcia de Castro Boller, Juigado em: 23 set. 2004. 
a incidência de encargos moratórios abusivos, e que não estivessem previstos contratualmente. Elevação do débito causada pelo vencimento das prestaçóes inadimplidas. De outra banda, os apelantes deixaram de pagar apenas $31 \%$ do preço, o que, no caso concreto dos autos, permite que se conclua pelo adimplemento substancial do contrato que, conforme a jurisprudência, impede a resolução do ajuste, cabendo apenas a cobrança do saldo devido. Lição da doutrina. PRIMEIRO APELO PARCIALMENTE PROVIDO, PREJUDICADO O SEGUNDO. UNANIME. ${ }^{30}$

Outra possibilidade de aplicação da boa-fé em se tratando de resolução contratual se verifica através do princípio que coíbe o "venire contra factum proprium".

Invocado pioneiramente na jurisprudência gaúcha pelo então Des. Rel. Ruy Rosado de Aguiar Júnior na Apelação Cível 589073956, julgada pela Quinta Câmara Civel do TJ/RS em 19/12/1989, cuja ementa merece transcrição:

BOA-FÉ. CONTRATO. O PRINCÍPIO DA BOA-FÉ IMPÓE DEVERES ANEXOS, DE ACORDO COM A NATUREZA DO NEGÓCIO E A FINALIDADE PRETENDIDA PELAS PARTES. ENTRE ELES SE ENCONTRA A OBRIGAÇÃO DA VENDEDORA DE PEQUENA LOJA DE VESTUÁRIO NÃO CANCELAR PEDIDOS JÁ FEITOS, COM O QUE INVIABILIZARIA O NEGÓCIO E FRUSTRARIA A JUSTA EXPECTATTVA DO COMPRADOR. VENIRE CONTRA FACTUM PROPRIUM. CONTRATO. A VENDEDORA DE LIJA DE VESTUÁRIO, QUE AUXILIA O COMPRADOR NOS PRIMEIROS DIAS DA NOVA ADMINISTRAÇÃO E ASSINA PEDIDOS DE NOVAS MERCADORIAS, NÃO PODE DEPOIS CANCELAR TODOS OS PEDIDOS AINDA NÃO RECEBIDOS, ASSIM INVIABILIZANDO A NORMAL CONTINUIDADE DO NEGÓCIO, SEM QUE PARA ISSO TENHA MOTIVO RAZOÁVEL. ACAO INDENIZATÓRIA JULGADA PROCEDENTE. APELO PROVIDO EM PARTE PARA REDUZIR A INDENIZAÇÃO."3

${ }^{30}$ RIO GRANDE DO SUL. Tribunal de Justiça, Apelação Cível No 70004835799. Relator: Pedro Luiz Pozza. Julgado em: 23 set. 2004.

${ }^{31}$ RIO GRANDE DO SUL. Tribunal de Justiça. Apelaçãa Civel 589073956. Relator: Rùy Rosado de Aguiar Júnior. Julgado em: 19 dè. 1989. 
O princípio, contudo, não foi devidamente desenvolvido pela jurisprudência, sendo de escassa aplicação no Tribunal gaúcho conforme se verifica mediante pesquisa realizada no site do TJ/RS pela expressão "venire contra factum proprium", obtendo-se como resultado somente um julgado de 03/03/2004 invocando expressamente principio em tema de resolução contratual., ${ }^{32}$

Sabe-se que o princípio de "venire contra factum proprium!", traduzido pela doutrina como "exercício de uma posição jurídica em contradição com o comportamento exercido anteriormente pelo exercente", encontra fundamento técnico-jurídico na ptoteção da confiança despertada na contraparte, razão pela qual a mesma pesquisa foi efetuada com a utilização da expressão "princípio da confiança".

Desta vez, encontramos um julgado ${ }^{33} \mathrm{em}$ que a resolução restou desautorizada em face da a fronta ao princípio da confiança que deve sempre nortear as relações contratuais. Tratava-se do caso de seguro de vida em grupo firmado pela Prefeitura Municipal de Batra do Ribeiro de quem a autora é funcionária. Tal seguro permitia, gratuitamente, a inclusão automática dos côníuges dos segurados, cuja morte beneficiaria o segurado principal. A seguradora, contudo, negava-se a pagar a indenização sob o argumento de que o seguro estava automaticamente cancelado porque a autora havia se separado judicialmente. No julgamento da apelação entendeu-se que o seguro estava em vigor em razão do comportamento anterior da seguradora que não havia destacado no contrato ou informado a beneficiária acerca da limitação da condição de beneficiátio como cônjuge ou companheiro do segurado. ${ }^{34}$

32 Trata-se a Apelação Civel 70008000275, Vigésima Camara Civel, cuja ementa ensina: AÇAO DE: RESOLUÇÃO CONTRATUAL. CESSÃO DE DIREITOS DE COMERCIALZAÇAOO DE JAZIGOS. AUSRNCIA DE REGRAMENTO CONVENCIONAL EXPRESSO QUANTO $A$ SITUACAO TRANSITÓRIA. COMPORTAMENTO DAS PARTES. NL VENIRLE CONTRA FACTUM PROPRIUM. NAO TENDO AS PARTES CUIDADO DI REGRAR SITUAÇAO TRANSITÓRIA, RILLATIVAMENTE AO INTERREGNO SITUADO ENTRE O CONTRATO E IMPLEMENTO DE CONDICAO SUSPLINSIVA, CUMPRE OBSERVAR O COMPORTAMENTO DLLAS, COMO FATOR REVELADOR DA COMPOSIÇAO DE INTLRESSES E RISPECTYVA NORMATIZAÇÃO QUL TERMTNOU POR SE ESTABELECER, DANDO A MLILHOR INTERPRETAÇÃO POSSIVIEL AO QUE FORA PACTUADO. (RIO GRANDIs DO SUL. Tribunal de Justiça. Apelação Cível 70008000275. Relator: Des. Aminio José Abreu Lima da Rosa)

3 RIO GRANDE DO SUL. Tribunal de Justiça. Apelação Civel 70000895334 . Julgado em: 16 nov. 2000.

${ }^{34}$ tixemplar é o voto do Des. Carlos Aberto Bencke, o qual merece transcrição: "Como bem ressaltou o ilustre magistrado singular, o contrato entre as partes firmado denominado "contrato de seguro de vida em grupo e acidentes pessoais" insere-se dentre aqueles de consumo, onde identifica-se o fornecedor do serviço e o consumidor ao qual é dirigida a prestação nas figuras da seguradora e segurado.

Analisando-se a presente quaestio sob este prisma, de inicio, pode-se afirmar, extreme de dúvidas, militar em favor da autora presunção relativa à boa-fé com que obrou no episódio em comento.

A avença entabulada pela Prefeitura da comarca de Barra do Ribeiro com a ré tendo por segurada a autora e scu marido, já que funcionários públicos municipaís, em apólices distintas figurando ambos 
Como visto, o princípio da boa-fé objetiva apresenta múltiplas funções e inúmeras possibilidades de aplicação aos casos de resolução, mas quando se está a tratar de contratos de consumo de longa duração, o princípio assume potencialidade máxima como elemento criador de novos deveres contratuais e princípio limitador do direito à tesolução. É o que demonstraremos na última parte deste trabalho.

\section{B. Valorização da catividade nos contratos de consumo e obrigação de renegociar}

Os contratos cativos de longa duração são um fenômeno da nova realidade contratual massificada, também são denominados na doutrina como "contratos múltiplos", "serviços contínuos", "relações contratuais triangulares", "contratos de serviços complexos de longa duração", etc.

Preferimos adotar a denominação utilizada pela professora Cláudia Lima Marques, que há algum tempo reflete sobre o tema, definindo o fenômeno como

uma série de novos contratos ou relações contratuais que utilizam os métodos de contratação de massa (através de contratos de adesão ou condições gerais dos contratos), para fornecer serviços especiais no mercado, criando relações jurídicas complexas, múltiplas e de longa duração, envolvendo uma

em reverso como beneficiários do seguro, mostra-se válida mesmo após a separação dos cônjuges, já que, como devidamente comprovado nos autos, nada informou a requerida acerca de possível cancelamento com a modificação do estado civil do casal.

Se é verdade que a demandante não obrou com a necessária transparência em relação à comunicação à seguradora sobre o processo de separação consensual findo entre os cônjuges, até por uma çuestão de desconhecimento do quão importante seria a conunicação do desfazimento do natrimônio, não é menos verdadeiro afirmar que este lapso pode ser atribuido, no minimo, concorrentemente, à conduta adotada pela demandada no transcorrer do seguro, pois da leitura da rubrica constante das apólices de seguro depreende-se que não há qualquer exigência quanto à limitação da condição do beneficiário como o cônjuge ou o companheiro do segurado, dando azo, desta forma, a interpretaçōes dúbias quanto à indicaçẫo ou substituiçâo do indicado independentemente de qualquer manutenção de vínculo. No caso em tela, repiso, näo houve a necessária informação à requerente por parte da requerida quanto à condição de ser o beneficiário e também segurado imprescindivelmente o cônjuge, assim como o desfazimento voluntário do vínculo marital importar no cancelamento automático do seguro, o que se tradu\% no agir de boa-fé por parte da segurada na continuidade e manutenção da avença securitária firmada, com a plena validade desta.

Destarte, presente a boa-fé por parte da segurada e beneficiária dos contratos com a ré entabulados, bem como o descumprimento por parte desta de seu dever essencial de informat, acarretando, de forma inequivoca, afronta ao princípio da confiança que deve sempre nortear as relaçóes contratuais, frustração dos interesses da parte, especificamente de sua contraprestação contratual, já que recebeu de forma integral o prêmio a requerida por parte do segurado falecido, outra não é a solução para o deslinde da quaestio jure senão a procedência clo pedido contido na exordial com o paganento do seguro por morte do segưurado à berieficiăria estipulada." 
cadeia de fornecedores organizados entre si e com uma característica determinante: a posição de catividade ou dependência dos clientes, consumidores. ${ }^{35}$

E segue com a bela lição sobrc o sentido de catividade:

Esta posição de dependência ou, como aqui estamos denominando, de catividade, só pode ser entendida no exame do contexto das relações atuais, onde determinados serviços prestados no mercado asseguram (ou prometem) ao consumidor e sua familia status, segurança, crédito renovado, escola ou formação universitária certa e qualificada, moradia assegurada ou mesmo saúde no futuro. A catividade há de ser entendida no contexto do mundo atual, de indução ao consumo de bens materiais e inateriais, de publicidade massiva e métodos agressivos de marketing, de graves e renovados riscos na vida em sociedade, e de grande insegurança quanto ao futuro.

Em interessante artigo, José Tadeu Neves Xavier identifica a catividade como um processo de sedução dos consumidores e a analisa em dois momentos. ${ }^{36}$ Inicialmente é representativa das técnicas de marketing utilizadas antes da formação do conrrato, de forma a convencer o contratante em relação às conveniências da contratação, visando chegar ao consumidor quando se encontra despreparado para resistir às tentações típicas da atual sociedade de consumo. Num segundo momento, a catividade é visiumbrada após a formação do contrato, onde a expressão passa a ser entendida como situação de dependência e fragilidade do consumidor frente ao contrato formado, o que faz con que aceite facilmente qualquer nova imposição desejada pelo fornecedor para manter o vínculo.

Dentre os exemplos principais de contratos cativos de longa duração podemos citar os contratos de crédito, contratos de seguro-saúde e assistência médico-hospitalar, contratos previdenciários, nos quais a promessa, de status, segurança, tranqüilidade aumentam significativamente a expectativa do consumidor que passa a contar com o contrato para enfrentar as adversidades no curso de sua vida.

Com base nos dois elementos essenciais que servem de referência a esses contratos, o tempo e a catividade, parece inevitável uma especial valorização do princípio da boa-fé objetiva, reforçando-se os deveres anexos informar, aconselhar, cooperar, dever de cuidado,

${ }^{35}$ MARQUES, Cláudia Lima. Contratos bancários em tempos pós-modernos: primeiras reflexões. Revista de Direito do Consumidor, São Paulo, n. 25, jan./mar.1998, p.18 a 38.

${ }^{36}$ XAVIER, José Tadeu Neves. Reflexões sobre os contratos cativos de longa duração. AJURIS, Porto Alegre, n. 95 , set. 2004, p. 141 
lealdade como instrumentos para a superação das vicissitudes ocorridas ao longo da contratação de modo que atinja seu fim econômico e social.

Com a passagem do tempo é natural que o contrato esteja mais suscetivel às mudanças externas de natureza objetiva como alteração do preço em razão de planos econômicos ou mesmo de ordem subjetiva como a perda do emprego, doença, divórcio, enfim, todas as circunstâncias que podem gerar dificuldades na manutenção do sinalagma inicial, possibilitando que os contratantes recorram ao Judiciário inclusive buscando a resolução do contrato.

Neste ponto, se faz necessário destacar que a resolução, embora algumas vezes seja a melhor alternativa para o reestabelecimento do equilibrio entre particulares ou empresários quando o pacto já não corresponde ao interesse de ambos, deve ser a última opção para os contratos cativos de longa duração porque acarreraria a frustração das expectativas legítimas do consumidor quanto à estabilidade do vínculo e sua boa conclusão.

O próprio Código de Defesa do Consumidor não veda a estipulação de cláusula resolutiva, desde que a opção fique a cargo do consumidor, mas deixa evidente sua pteferência pela manutenção dos contratos no parágrafo $2^{\circ}$ do art. 51 :

A nulidade de uma cláusula contratual abusiva não invalida 0 contrato, exceto quando de sua ausência, apesar dos esforços de integração, decorrer ônus excessivo a qualquer das partes.

A reforçar o mandamento geral de manutenção dos contratos, 0 art $6^{\circ}$, V do Código de Defesa do Consumidor prevê como direito básico do consumidor a modificação das cláusulas contratuais que estabelcçam prestaçôes desproporcionais ou sua revisão em razão de fatos supervenientes que as tornem excessivamente onerosas. Para o exercício desse direito, fica dispensada a prova do caráter imprevisivel do fato superveniente, bastando a demonstração objetiva da onerosidade excessiva advind a para o consumidor.

Ainda assim encontramos na jurisprudência do Tribunal de Justiça gaúcho e do Superior Tribunal de Justiça somente ações revisionais com fundamento em fatos supervenientes de natureza objetiva, a exemplo dos contratos de leasing com previsão de reajuste pelo dólar americano que tiveram os preços consideravelmente elevados em face da desvalorização da moeda nacional frente à moeda estrangeira. ${ }^{37}$

O assunto me preocupa sobremaneira porque no exercício da jurisdição chama a atenção o expressivo número de ações de cumprimento (ações de cobrança, ações executivas) ajuizadas, em sua maioria, por bancos e financeiras, em razão do inadimplemento dos

37 Veja a análise de alguns desses julgados em MARQUES, Cláudia Lima; BENJAMTN, Antônio Herman J: MIRAGEM, Bruno. Comentários ao código de defesa do consumidor. São Paulo: Revista dos Tribunais, 2003. 
devedores/consumidores. Estes, a seu turno, ajuizam sistematicamente ações buscando a revisão dos mais diversos contratos bancários que abarrotamo Judiciário, sempre alegando que a onerosidade excessiva das prestações.

Não disponho de dados oficiais, mas a realidade leva a crer que o fenômeno do superendividamento, que se iniciou nos Estados Unidos e expandiu seus efeitos nocivos para o continente eutopeu, já é uma realidade nacional que exige uma reação da ciência do Direito. Segundo definição de Maria Manuel Leitão Marques em monografia sobre o tema,

o sobreendividamento, também designado por falência ou insolvência de consumidores, refere-se às situações em que o devedor se vê impossibilitado, de uma forma durável e estrutural, de pagar o conjunto de suas dividas, ou mesmo quando existe uma ameaça séria de que não possa fazer no momento em que elas se tornem exigiveis. ${ }^{38}$

A professora Cláudia Lima Marques, a quem os novos fenômenos atinentes ao direito do consumo nunca passam despercebidos, destina alguma reflexões importantes sobre o assunto. ${ }^{39} \mathrm{E}$, com o fito de aprofundar c adeqüar o estudo à realidade nacional, elaborou e coordenou pesquisa científica inédita acerca do perfil dos consumidores gaúchos superendividados. Os questionários foram aplicados pela Defensoria Pública na Grande Porto Alegre ${ }^{\text {th }}$ para cerca de 100 consumidores e os resultados confirmaram aquela constatação empírica de que o superendividamento pode ser a causa da insolvência do consumidor brasileiro.

Dentre os dados pesquisados constatou-se que $90 \%$ dos entrevistados estavam com o pagamento das prestaçôes em atraso, que $80 \%$ dos credores eram bancos e financeiras e que apenas $30 \%$ dos endividados eram ativos, ou seja, aqueles que não souberam administrar seu orçamento, que gastaram mais do que ganhavam.

Dentre os entrevistados, $70 \%$ se encontravam endividados em razão de fatos supervenientes de natureza subjetiva, $36,2 \%$ em razão de desemprego, $18,1 \%$ por doença $, 7,9 \%$ por divórcio/separação e $5,1 \%$ por morte. Estes são denominados na doutrina por "endividados passivos", isto é, que se enconrram impossibilitados de pagar suas dívidas por força de agentes externos, por circunstâncias alheias à sua vontade ou atuação.

O resultado final da pesquisa demonstrou que o endividamento já atinge inclusive a população de baixa renda que depende do crédito para a satisfação de necessidades básicas

${ }^{38}$ MARQUES, Maria Manuel Leitão. O endividamento dos consumidores. Lisboa: Almedina, 2000, pág. 2

39 MARQUES, Contratos...

40 O questionário foi aplicado nas Comarcas de Porto Alegre, Barra do Ribeiro, Charqueadas, Gravataí, Guaiba, Montencgro, Sapucaia do Sul, São Leopoldo, São Sebastião do Cá e Taquara. 
às quais não satisfaria com o minguado salátio. População que não resiste aos apelos da publicidade veiculada pela televisão, internet, telefone entre outros métodos agressivos como a panfletagem, o que nos faz concluir que o endividamento é fruto da sociedade de massas que incentiva cada vez mais o consumo e, nesta perspectiva deve ser tratado, não mais como um fato individual, mas como um problemá social com evidentes reflexos na economia como um todo.

E, justamente, neste momento em que a facilidade ao crédito está em plena eclosão, é chegada a hora do Judiciário enfrentar o tema do endividamento ainda que não disponha de instrumentos legais específicos como a França que já possui lei regulando o tema. ${ }^{43} \mathrm{E}$ preciso desde já lançar mão dos instrumentos legais disponíveis, em especial do Código de Defesa do Consumidor, sempre com uma leitura renovada - adaptada às modíficações sociais - que é proporcionada pelo princípio da boa-fé obje tiva.

Tratando-se de relações de consumo, em que o comprador está sujeito às mais variadas seduções das técnicas de venda aliadas à ilusão de crédito fácil, impende que se teveja o conceito de inadimplemento, ou melhor, as simações em que se verifica a mora, atenuando os seus efeitos em relação aos consumidores que não agiran com dolo ou com a finalidade de causar dano ao credor, mas que em virtude de dificuldades pessoais, sejam de ordem econômica, ptofissional ou familiar, se viram impossibilitados de cumprir sua prestação.

Desse modo, chega-se à conclusão inelutável de que as circunstâncias subjetivas passivas mencionadas nos contratos cativos de longa duração também deveriam ser aceitas como causas justas de inadimplemento não imputáveis ao devedot ou não culpáveis (para aqueles que não dispensam o elemento subjetivo da mora) afastando a tesolução evenmalmente postulada pelo credor e, mais, impondo ao fornecedor um dever de renegociar o débito.

Não se pode olvidar, afinal, que a boa-fé objetiva também tem a função de correção e adaptação em caso de mudança das circunstâncias, o que permite que o julgador, mesmo na ausência do art. $6^{\circ} \mathrm{V}$ do Código de Defesa do Consumidor, adapte e modifique o contrato visando a manutenção do vínculo.

41 A lei 89-1010, de 31 de dezernbro, diploma que ficou conhecido como Lei Nejertz, por ser sua autora a entäo Ministra responsável pelas questões de consumo, Véronique Neiertz, veio consagrar um regime dedicado ao tratamento das situações de superendividamento dos particulares. Em 1995 toi objeto de uma primeira reforma (Lei $n^{\circ} 95-125$, de 8 de fevereiro) e em 1998 teve lugar uma nova revisão (Lei : $^{\circ} 98-657$, de 29 de julho). Este procedimento passou, desde 1993, a estar integrado no Código de Consumo, nos artigos L 331-1 a L 333-8. A novidade do regime consagrado em 1989 residiu na criação de um sistema de tratamento coletivo das dívidas não profissionais dos particulares superendividados, permitindo-lhes obter un esquema global de pagamento em que são envolvidos todos os credores, em lugar de terem de negociar cada dívida com cada credor isoladamente. 
De outro lado, quando se verifica a situação de superendividamento, a manutenção do contrato pode não se afigurar razoável diante da evidente impossibilidade do consumidor de cumprir as prestações futuras. Nesse caso, o consumidor teria o direito de optar pela rescisão do contrato mesmo que inadimplente (Art. $54 \$ 2^{\circ}$ e Art. 51 , XI do CDC).

A jurisprudência do Superior Tribunal de Justiça está se consolidando na direção de permitir, dependendo da causa do inadimplemento, que o consumidor pleiteie a resolução do negócio. ${ }^{42}$ Quando do julgamento do RESP 109.331/SP, o Ministro Ruy Rosado de Aguiar assim enfrentou o controvertido tema:

O devedor inadimplente não tem, em princípio, o direito de pedir a resolução do contrato. Porém, se surgir fato superveniente, suficientemente forte para justificar aquele inadimplemento, a parte que sofreu o efeito dessa alteração objetiva da base em que foi celebrado o negócio pode vir a juízo para provocar a extinção do contrato. Aceita essa premissa, a jurisprudência tem reconhecido como fato suficiente para a resolução a posterior impossibilidade relativa de cumprir o contrato, por efeito da desvalorização da moeda e da implantação de planos econômicos e critérios de atualização das dívidas que desequilibram o orçamento do devedor e o impedem de continuar cumprindo o contrato. Nessa circunstância, pode o devedor tomar a iniciativa da propositura da ação de rescisão.

Concluindo, na nova teoria contratual positivada no Código de Defesa do Consumidor e, agora, no Código Civil de 2.002 , a resolução contratual deve ser aplicada à luz da boa-fé objetiva que proporcionará uma leitura renovada do instituto de forma a evitar a ruína do consumidor, prevenindo, mesmo que de forma indireta, os problemas decorrentes do superendividamento.

\section{CONSIDERAÇÕES FINAIS}

Efetivamente, a resolução contratual é um dos institutos mais importantes no Direito das Obrigações, o que se verifica pelo considerável número de estudiosos que se debruçam sobre a matéria e, igualmente, pelo elevando número de demandas envolvendo o tema. Contudo, apesar de sua relevância prática, contamos com parco regime legal, aparentemente pouco inovador, como delineado na primeira parte deste trabalho.

\footnotetext{
42 Nesse sentido os precedentes citados pela professora Cláudia Lima Matques em obra já citada (RESP 200.019/SP, 109.960/RS, RESP 132.903/SP, RESP 79.489/DF)
} 
Não obstante, sua aplicação pode ganhar feição nova se interpretado sob uma nova ótica, ou melhor, com as lentes da boa-fé objetiva, princípio norteador de todas as relações de direito privado. O princípio, como vimos, pode auxiliar tanto na apreciação da presença dos requisitos para a resolução como também para coibir abusos nạ sua aplicação.

Nesta altura , a lição do mestre Clóvis do Couto e Silva parece cada vez mais adequada à realidade atual quando assinala que;

O princípio da boa-fé endereça-se sobretudo ao juiz e o instiga a formar instituições para responder aos fatos novos, exercendo um controle corretivo do Direito estrito, ou enriquecedor do conteúdo da relação obrigacional, ou mesmo negativo em face do direito postulado pela outra parte. A principal função é a individualizadora, em que o juiz exerce atividade similar à do pretor romano, criando o "Direito do caso". O aspecto capital para a criação judicial é o fato de a boa* fé possuir um valor autônomo, não relacionado com a vontade. Por ser independente da vontade, a extensão do conteúdo da telação obrigacional já não se mede com base somente nela, e, sim, pelas circunstâncias ou fatos referentes ao contrato, permitindo-se "construir" objetivamente o regramento do negócio jurídico, com a admissão de um dinamismo que escapa, por vezes, até mesmo ao controle das partes. Essa concepção objetiva da relação obrígacional assemelha-se, muito embora a diversidade conceitual, à interpretação objetiva da lei. ${ }^{43}$

Nos contratos de consumo, o princípio da boa-fé objetiva tem ainda maior opetatividade, porquanto maior a possibilidade de intervenção do Estado no contéudo da avença e, conseqüentemente, maior a limitação da autonomia privada. Sobretudo com o fenômeno do superendividamento, impulsionado pelo consumo em massa e agressivas técnicas de venda, a boa fé objetiva pode ser utilizada como instrumento para reequilibrar a justiça contratual, quiçá impondo ao credor um dever de renegociar, evitando a exclusão dos consumidores do mercado .

${ }^{43}$ COUTO E SILVA, Clóvis do. O princípio da boa-fé no direito brasileiro e português. In: FRADLiRA, Vera Maria Jacob de (Org). O direito privado brasileiro na visão de Clóvis do Couto e Silva, Porto Alegre: Livraria do Advoggado, 1997, p. 42. 


\section{REFERÊNCIAS BIBLIOGRÁFICAS}

AGUIAR JÚNIOR, Ruy. Os contratos bancários e a jurisprudência do Superior Tribunal de Justiça. Revista dos Tribunais, São Paulo, n. 811, p. 99 a 141, maio de 2003. 2003 .

Extinção dos contratos por incumprimento do devedor. Rio de Janeiro: Aide,

ALVIM, Agostinho. Da inexecução das obrigações e suas conseqüências. 4. ed. São Paulo: Saraiva, 1972.

ASSIS, Araken de. Resolução do contrato por inadimplemento. São Paulo: Revista dos Tribunais, 2004.

BRANCO, Gerson Luiz Carlos. A proteção das expectativas legitimas derivadas das situações de confiança: elementos fomadores do principio da confiança e seus efeitos. Revista de Direito Privado, São Paulo, n 12, p. 169-225, out./dez. 2002.

CARRIERO, Giuseppe. Tratado di diritto privato: autonomia privata e disciplina del mercato. If credito al consum. Torino: G. Giappicheli, 2002. v. 31.

CAVALIERI FILHO, Sérgio. Programa de responsabilidade civil. São Paulo: Malheiros, 2003.

COSTA, Mário Júlio Brito de Almeida. Direito das Obrigações.Coimbra: Livraria Almedina, 1979

FRADERA, Vera Maria Jacob de (Org). O direito privado brasileiro na visão de Clóvis do Couto e Silva. Porto Alegre: Livraria do Advogado, 1997.

GHERSI, Carlos Aberto. Contratos civiles y comerciales. Buenos Aires: Astrea, 1990.

GOMES, Orlando. Contratos. 22.ed. Rio de Janeiro: Forense, 2000.

. Obrigações. Rio de Janeiro: Forense,1988.

GRASSO, Biagio. Eccesione d'inadempimento e risolucione del contratto. Camerino: Scuola de perfezionamento in diritto civile dell' Università di Camerino, 1973.

LARENZ, Karl. Base del negócio jurídico y cumplimiento de los contratos. Granada: Comares, 2002.

Derecho de obligaciones. Madrid: Revista de Derecho Privado, 1958. 2 v.

MARQUES, Cláudia Lima. Boa-fé nos serviços bancários, financeiros, de crédito e securitários e o código de defesa do consumidor: informação, cooperação e tenegociação? Revista da Faculdade de Direito da Universidade Federal do Rio Grande do Sul, Porto Alegre, v. 22, p. $47-83,2002$. 
Contratos bancários em tempos pós-modernos-primeiras reflexões, Revista de Direito do Consumidor, São Paulo, n.25, p.20-38 jan./mar. 1998.

. Os contratos de crédito na legislação brasileira de proteção ao consumidor. Revista de Direito do Consumidor, São Paulo, n.18, p.53-, abr./jun.1996

Contratos no código de defesa do consumidor. 4 ed. São Paulo: Revista dos Tribunais, 2002.

- Direitos básicos do consumidor na sociedade pós-moderna de serviços: o aparecimento de um sujeito novo e a realização de seus direitos. Revista de Direito do Consumidor, São Paulo, n.35, p 61 , jul./set. 2000.

Planos privados de assistência à saúde. desnecessidade de opção do consumidor pelo novo sistema: opção a depender da conveniência do consumidor. abusividade de cláusula contratual que permite a tesolução do contrato coletivo por escolha do fornecedor. Revista de Direito do Consumidor, São Paulo, n.31, p. 129-169 jul./set.1999.

Proposta de uma teoria geral dos serviços com base no código de defesa do consumidor: Revista de Direito do Consumidor, São Paulo, n. 33, p.79, jan./mat. 2000.

Sociedade de informação e serviços bancários: primeiras reflexões. Revista de Direito do Consumidor, São Paulo, n. 39, jul./set. 2001

MARQUES, Cláudia Lima; BENJAMIN, Antônio Hermann; MIRAGEM, Bruno. Comentários ao código de defesa do consumidor. São Paulo: Revista dos Tribunais, 2003.

MARQUES, Maria Manuel Leitão. O endividamento dos consumidores. Lisboa: Almedina, 2000.

MARTINS-COSTA, Judith. A boa-fé no direito privado. São Paulo: Revista dos Tribunais, 2000.

MARTINS-COSTA, Judith. Comentários ao novo código civil. Rio de Janeiro: Forense, 2003. v. 5 , t. 2 .

MENDONÇA, Manuel Ignacio Carvalho de. Doutrina e Prática das Obrigações. Rio de Janeiro: Revista Forense, 1956. v. 1.

MENEZES, Antônio Manuel da Rocha. Cordeiro. Da boa-fé no direito civil. Coimbra: Almedina, 2001.

Direito das obrigações. Lisboa: Associação Acadêmica da Faculdade de Direito de Lisboa, 1980.

Tratado de direito civil português. Coimbra: Almedina, 2000. V. 1 - Parte geral.

MIRANDA, Francisco Cavalcanti Pontes de. Tratado de direito privado. Rio de Janeiro: Bookseller, 2003. v. 23. 
MITIDIERO, Daniel Francisco, Resolução contratual: delineamentos e efeitos. Revista Síntese de Direito Civil e Processual Civil, São Paulo, n. 8, p.35-, nov./dez. 2000.

MONTEIRO, Washington de Barros. Curso de Direito Civil.. São Paulo: Saraiva, 1995, v.4 e 5 - Direito das Obrigações

OPTIZ, Oswaldo. Mora no negócio jurídico: doutrina e jurisprudência. São Paulo: Saraiva, 1984

RIZZARDO, Arnaldo. Direito das Obrigações. Rio de Janeiro: Forense, 2004.

SILVA, Clóvis do Couto e. A obrigação como processo. São Paulo: Bushstasky, 1976.

. O princípio da boa-fé no direito brasileiro e português. In: FRADERA, Vera Maria Jacob de (Org.). O direito privado brasileiro na visão de Clóvis do Couto e Silva", Porto Alegre: Livraria do Advogado, 1997.

USTÁRROZ, Daniel. A resolução do contrato no novo código civil. Revista Jurídica, Porto Alegre, n. 304, p. 32-53, fev. 2003.

VARELA, João de Matos Antunes. Das obrigações en geral. Coimbra: Almedina, 1994. $2 \mathrm{v}$.

XAVIER, José Tadeu Neves. Reflexões sobre os contratos cativos de longa duração. AJURIS, Porto Alegre, n. 95, p. 137-159, set. 2004. 